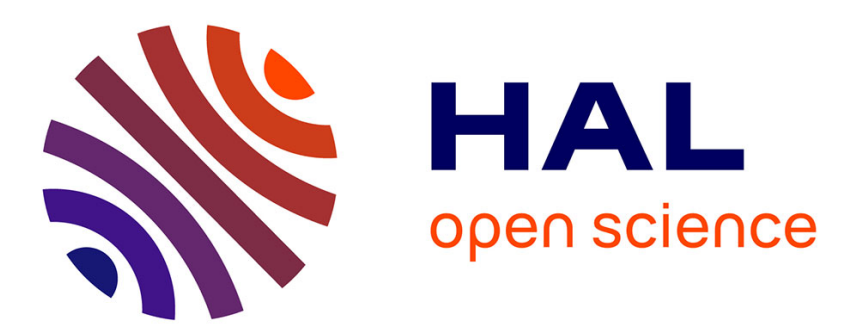

\title{
Relative behaviour of electrical conductance for solid and molten mercuric halides
}

\author{
K.K. Srivastava, A. Kumar, D.R. Goyal
}

\section{To cite this version:}

K.K. Srivastava, A. Kumar, D.R. Goyal. Relative behaviour of electrical conductance for solid and molten mercuric halides. Revue de Physique Appliquée, 1979, 14 (3), pp.465-468. 10.1051/rphysap:01979001403046500 . jpa-00244615

\section{HAL Id: jpa-00244615 https://hal.science/jpa-00244615}

Submitted on 1 Jan 1979

HAL is a multi-disciplinary open access archive for the deposit and dissemination of scientific research documents, whether they are published or not. The documents may come from teaching and research institutions in France or abroad, or from public or private research centers.
L'archive ouverte pluridisciplinaire HAL, est destinée au dépôt et à la diffusion de documents scientifiques de niveau recherche, publiés ou non, émanant des établissements d'enseignement et de recherche français ou étrangers, des laboratoires publics ou privés. 


\title{
REVUE DE PHYSIQUE APPLIQUÉE
}

\section{Relative behaviour of electrical conductance for solid and molten mercuric halides}

\author{
K. K. Srivastava. A. Kumar and D. R. Goyal \\ Department of Physics. Panjab University, Chandigarh, India
}

(Reçu le 31 janvier 1978, accepté le 24 novembre 1978)

\begin{abstract}
Résumé. - On étudie les conductance et capacité électrostatique des halides de mercure solide. La comparaison des valeurs avec halides de mercure en fusion montre que l'influence de la température et pression sur la conductance électrique est la même pour les deux systèmes, qui sont très différents.
\end{abstract}

\begin{abstract}
The paper reports the conductance and capacitance measurements on solid mercuric halides with a view to compare the results reported for molten mercuric halides. The study reveals that the temperature and pressure dependence of their electrical conductance remains unaltered for the two systems which are so widely different.
\end{abstract}

1. Introduction. - Considerable amount of work has been reported [1-9] on molten mercuric halides relating to their electrical conductivity. Darnell and McCollum [10] have lately reported their interesting measurements of conductivity for molten $\mathrm{HgCl}_{2}$ and $\mathrm{HgI}_{2}$ at elevated pressures upto $22 \mathrm{kbar}$. A summary of their important findings is worth a mention. For molten $\mathrm{HgCl}_{2}$ they observed that (i) the material has a low conductivity and therefore remains slightly dissociated, (ii) an increase in pressure brings about a large increase in conductivity which will go back to its original value after the pressure is released, (iii) the temperature dependence of the isobaric conductance at an elevated pressure can, to a first approximation, be represented by the Arrhenius equation

$$
K=A \exp \left(-\frac{E_{\mathbf{k}}}{R T}\right),
$$

and (iv) their measurements tend to support the suggestion made by Grantham and Yosim [8], i.e., the system becomes more molecular with decreased density when heated at ordinary pressures. For molten $\mathrm{HgI}_{2}$, however, their only important observation was that an increase in pressure causes a decrease in conductivity.

While reporting measurements upon solid $\mathrm{HgCl}_{2}$ and $\mathrm{HgI}_{2}$ at very low pressure (atmospheric, and few hundred bars), the present authors provide an interesting evidence which indicates a great similarity in the behaviour of molten and solid mercuric halides even when the later is subjected to a very low pressure as compared to the former. In addition to conductance, we have also made capacitance measurements and our results indicate that almost all the characteristics, mentioned above for molten $\mathrm{HgCl}_{2}$ and $\mathrm{HgI}_{2}$, remain the same for the solid material as well. In case of $\mathrm{HgI}_{2}$, however, our results indicate that the solid material predominantly exists as a molecular species.

2. Experimental. - Powders of $\mathrm{HgCl}_{2}$ (A. R., Allied Chemicals, Canada) and $\mathrm{HgI}_{2}$ (A. R., Mallinckrodt Chemical Works, New York) were finely ground and compressed to a known pressure to form very thin strong pellets (thickness $\approx 0.075 \mathrm{~cm}$; dia $\approx 0.67 \mathrm{~cm}$ ). The measurements of capacitance were made on an instrument described earlier [11], having an accuracy of $0.0005 \mathrm{pF}$. The instrument remains stable within $\pm 0.001 \mathrm{pF}$ during a period of two hours. The conductance was measured on a B.P.L. megohmmeter, type RM 160/3. Both for conductance and capacitance measurements, the pellet is locked tight between the electrodes, having the same dimension as of pellet, of a sample holder with a thermostatic jacket through which a temperature-controlled liquid was circulated during the course of measurements.

The time dependent measurements of capacitance and conductance were made in the following manner. After compressing the material to a known pressure, the pellet was immediately taken out of the die and transferred to the sample holder for measurements at atmospheric pressure. Care was taken to consume 
minimum time (one minute) in the process of transfer. By using a device [12], it was made sure that the pellet did not change its dimensions during the course of measurements.

3. Results. - 3.1 MerCuriC ChlORIDE. - Darnell and McCollum [10] observed that an increase in pressure brings about a large increase in conductance of molten $\mathrm{HgCl}_{2}$. Figure 1 shows the results of our

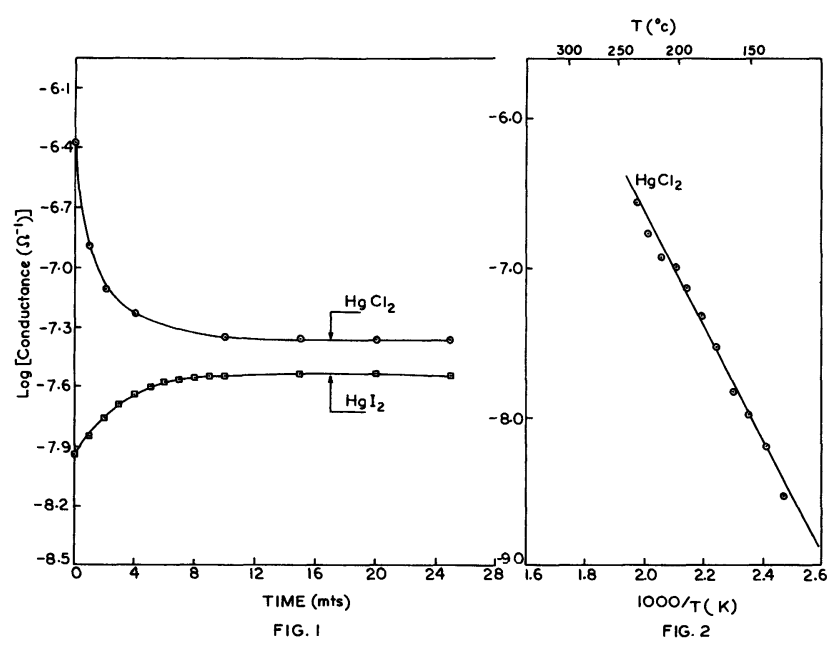

Fig. 1. - Variation of conductance as a function of time, immediately after the release of pressure ( 500 bar).

Fig. 2. $-\log K$ vs $1000 / T$ for solid $\mathrm{HgCl}_{2}$.

measurements made at room temperature for solid $\mathrm{HgCl}_{2}$. Immediately after the application of pressure (only 500 bar), the conductance of the material increased. But this increase was temporary, because after the release of pressure $(t=0$, Fig. 1 ), the conductance started decreasing rapidly in the beginning and thereafter reached a steady state to its value at atmospheric pressure. Such a reversible character of conductivity was also observed by Darnell and McCollum for molten $\mathrm{HgCl}_{2}$. Figure 3 shows the results of temperature dependence of conductance at atmospheric pressure for solid $\mathrm{HgCl}_{2}$. We observed that the conductance passes through a minimum around $90^{\circ} \mathrm{C}$.

Darnell and McCollum pointed out that their data on molten mercuric halides [10] and molten bismuth trihalides [13] at elevated pressures tend to support the suggestion made by Grantham and Yosim [8]. Incidentally, our results (shown in Figs. 1 and 3) are also consistent with the suggestion of Grantham and Yosim, i.e., the system becomes more molecular (less conducting) with decreased density.

Figure 1 directly confirms the above statement. The compression of the material causes an increase in density and, according to Grantham and Yosim, the system should become less molecular (or more ionic) which results into a temporary increase in conductance as observed by us. After the release of

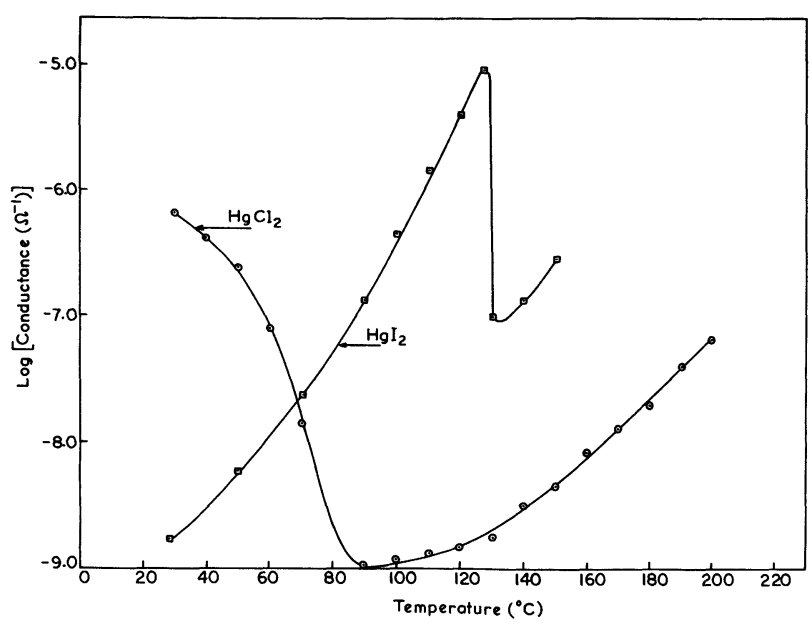

Fig. 3. - Temperature dependence of conductance for solid $\mathrm{HgCl}_{2}$ and $\mathrm{HgI}_{2}$ at atmospheric pressure.

pressure, the enhanced ionicity, produced due to compression, will slowly disappear and eventually the conductance of the system will decrease gradually till a steady state is reached (see Fig. 1). Similar arguments can be given for the results shown in figure 3. The initial fall in conductance can also be explained on the basis of suggestion made by Grantham and Yosim, because heating causes a reduction in density. As the temperature is increased above $90^{\circ} \mathrm{C}$, the dissociation seems to play a dominant role and therefore conduction keeps increasing with temperature.

Darnell and McCollum pointed out the validity of Arrhenius equation for the molten system of $\mathrm{HgCl}_{2}$. We have also observed that beyond $90^{\circ} \mathrm{C}$, the conductance $(K)$ of the solid system can, to a first approximation, be represented by Arrhenius equation

$$
K=A \exp \left(-\frac{E_{\mathrm{k}}}{R T}\right)
$$

This is evidenced by the plot of $\log K$ vis. $1000 / T$ shown in figure 2 . The value of activation energy for conduction $\left(E_{\mathbf{k}}\right)$, calculated from the data of figure 2 , is $17.5 \mathrm{kcal} / \mathrm{mole}$ as against $8.46 \mathrm{kcal} / \mathrm{mole}$ obtained by Darnell and $\mathrm{McC}$ Collum for molten $\mathrm{HgCl}_{2}$ at a pressure of $5.4 \mathrm{kbar}$. It is not surprising to see that the activation energy for conduction increases if one goes from a molten to a solid-state system.

The striking feature of the above study is that the conductance behaviour of solid $\mathrm{HgCl}_{2}$ remains the same as that of molten $\mathrm{HgCl}_{2}$. The object of the present work is indeed to emphasize upon the similarity of behavirol characteristics without attaching any importance to the absolute values of $K$ and $E_{\mathbf{k}}$ for the two situations.

3.2 MerCURIC IODIDE. - Figures 3 and 4 show the results of our measurements for the temperature dependence of conductance and capacitance of solid $\mathrm{HgI}_{2}$ at atmospheric pressure. In both the cases, a 
transition peak is obtained at $127^{\circ} \mathrm{C}$. It is well known that $\mathrm{HgI}_{2}$ undergoes a polymorphic transition from red to yellow at a temperature $127^{\circ} \mathrm{C}$. A hysteresis was observed during the cooling cycle for capacitance measurements, as shown in figure 4.

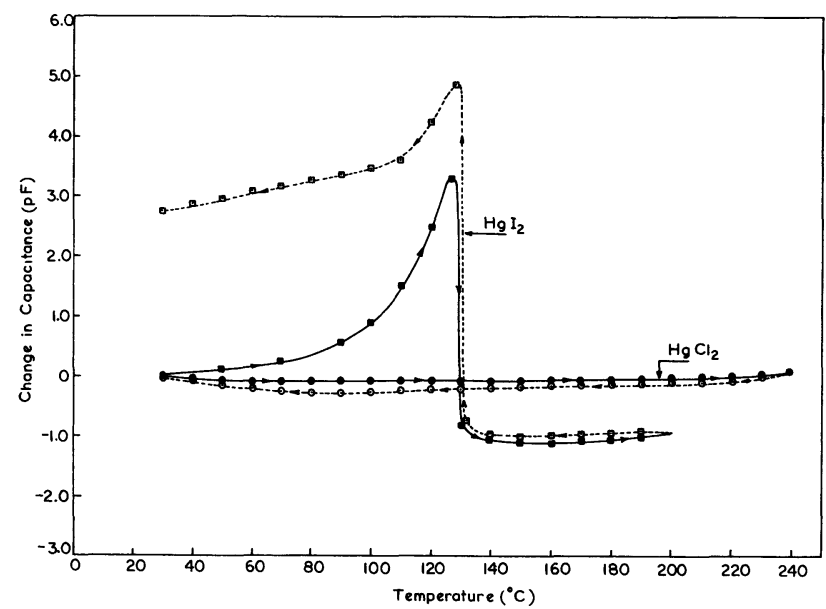

Fig. 4. - Temperature dependence of capacitance for solid $\mathrm{HgCl}_{2}$ and $\mathrm{HgI}_{2}$ at atmospheric pressure.

The effect of pressure on the capacitance of solid $\mathrm{HgI}_{2}$ is rather more interesting. Figure 5 gives the results of these measurements made immediately after the application of pressure which was only 500 bar at room temperature. One can easily see that the pressure causes a temporary reduction in the electrical capacitance which gradually increases to a steadystate value corresponding to the capacitance at atmospheric pressure. The phenomenon is reversible in the sense that if the same pellet is again compressed then its capacitance will again go down and thereafter would increase to reach the same steady state value. In our earlier communication [14], we have discussed at length that solid $\mathrm{HgI}_{2}$ predominantly exists as molecular species and application of pressure causes a slight change in the I-Hg-I angle which results into a change in the value of dipole moment in a manner that causes a reduction in the value of dielectric constant or capacitance. What we wish to emphasize here is that solid $\mathrm{HgI}_{2}$ exists mainly as molecular species at room temperature, as otherwise the measured capacitance of the system would not be so sensitive to temperature and pressure. This is obviously not true with solid $\mathrm{HgCl}_{2}$ whose capacitance remains insensitive to temperature and pressure (see Figs. 4 and 5). This further confirms our earlier statement that ionic species play a dominant role in the observed behaviour of solid $\mathrm{HgCl}_{2}$.

Figure 1 gives the effect of pressure on the conductance of solid $\mathrm{HgI}_{2}$. Unlike $\mathrm{HgCl}_{2}$, the conductance of $\mathrm{HgI}_{2}$ decreases when the material is compressed only to a pressure of 500 bar. After the release of pressure, the conductance gradually increases to reach a steady-state corresponding to its value at atmosphe-

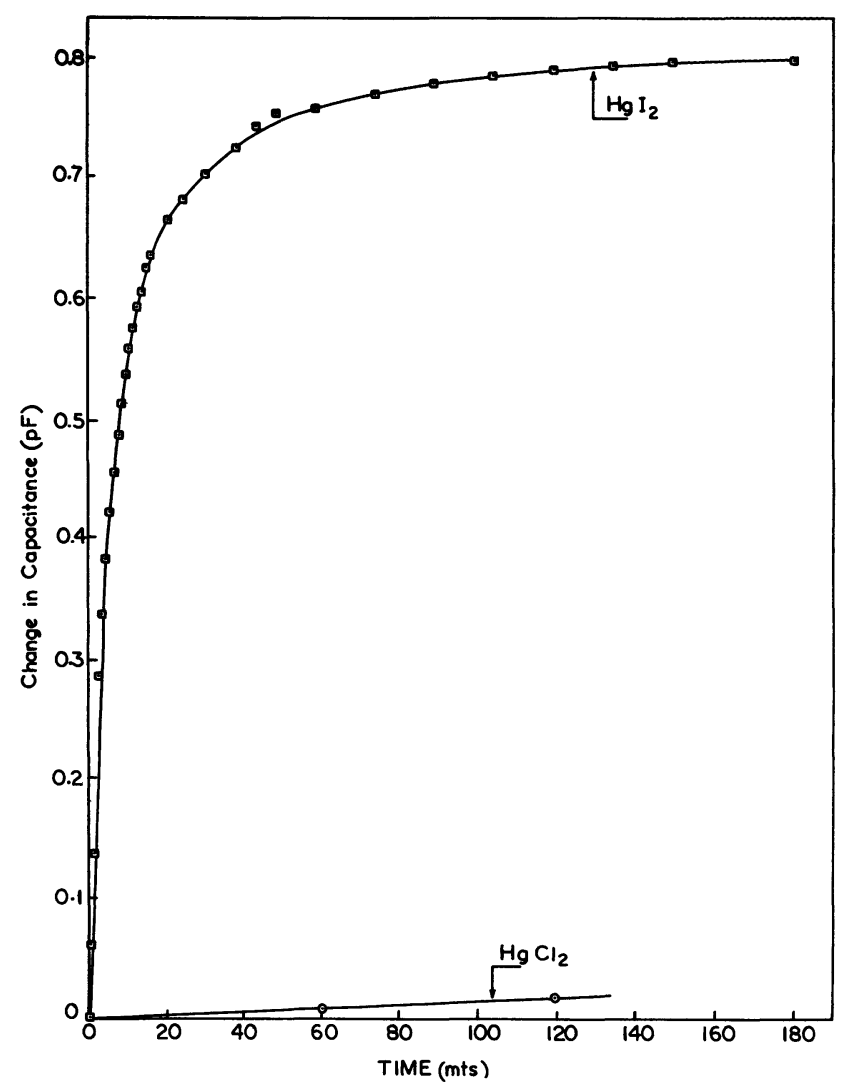

Fig. 5. - Pressure dependence of capacitance for solid $\mathbf{H g C l}_{2}$ and $\mathrm{HgI}_{2}$ at room temperature.

ric pressure. The reversible character of conductance has also been reported by Darnell and McCollum [10] for molten $\mathrm{HgI}_{2}$. Their other finding too is in agreement with what we have observed, i.e., reduction in conductance with increasing pressure. Darnell and McCollum reported two sets of different measurements, e.g., (i) temperature dependence of conductance at a fixed pressure of $5.4 \mathrm{kbar}$ (ii) the pressure dependence of conductance at a fixed temperature of $555 \pm 5^{\circ} \mathrm{C}$. The straight-forward measurement in case (ii) showed that the conductance of molten $\mathrm{HgI}_{2}$

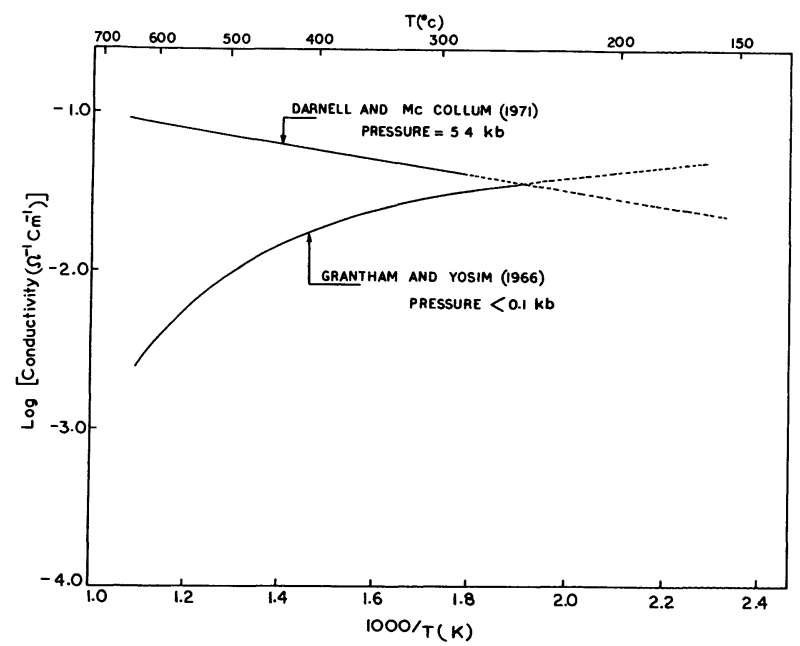

Fig. 6. - Temperature dependence of conductance for molten $\mathrm{HgI}_{2}$ at pressures $<0.1 \mathrm{kbar}$ and $5.4 \mathrm{kbar}[8],[10]$. 
decreased when the pressure was increased from $3 \mathrm{kbar}$ to $20 \mathrm{kbar}$. Whereas their isobaric measurements (case i) dont seem to be so apparent and therefore need an explanation. In figure 6 we have shown the conductance behaviour as observed by Darnell and McCollum [10] and Grantham and Yosin [8] (full lines). The two curves clearly indicate that at any given temperature, the conductance of the material increases if the pressure is increased from about $0.1 \mathrm{kbar}$ to $5.4 \mathrm{kbar}$. It may however be noted that the magnitude of increase in conductance goes on decreasing at relatively lower temperatures. If we extrapolate the curves to still lower temperatures (dotted lines) then, by way of argument, one can say that the reverse might happen. In other words, the conductance at $5.4 \mathrm{kbar}$ will be lesser than the conductance at $0.1 \mathrm{kbar}$ for temperatures below $250^{\circ} \mathrm{C}$ which is in agreement with what we have observed for solid $\mathrm{HgI}_{2}$ at room temperature.

One can therefore conclude that the temperature and pressure dependence of conductance of mercuric halides seems to remain unaltered for the two systems which are so widely different, i.e., Molten and solid state.

Acknowledgment. - Two of us, (A. K.) and (D. R. G.), are grateful to C.S.I.R. and U.G.C. for providing financial assistance.

\section{References}

[1] Hevesy, G. V., Kgl. Danska Videnskab, Selskab. Mat. Fys. Medd. 3 (1921) 13

[2] Klemm, W. and Biltz, W., Z. Anorg. Allgem. Chem. 152 (1926) 225.

[3] Bockris, J. O. M., Crook, E. H., Bloom, H. and Richards, N. E., Proc. Roy. Soc. (London) A 255 (1960) 558.

[4] Janz, G. J. and McInTYre, J. E. E., Ann. N.Y. Acad. Sci. 79 (1960) 761.

[5] Topol, L. E. and Ransom, L. D., J. Phys. Chem. 64 (1960) 1339.

[6] JANZ, G. J. and McIntYre, J. E. E., J. Electrochem. Soc. 109 (1962) 842.

[7] Sundheim, B. R., Fused Salts (McGraw-Hill, New York) 1964 , p. 36.
[8] Grantham, L. F. and Yosim, S. J., J. Chem. Phys. 45 (1966) 1192.

[9] Brasch, J. W., Melveger, A. J. and Lippincott, E. R., Chem. Phys. Lett. 3 (1968) 99.

[10] Darnell, A. J. and McCollum, W. A., J. Chem. Phys. 55 (1971) 116.

[11] Meredith, C. C. and Wright, G. F., Can. J. Tech. 33 (1955) 182.

[12] Bedard, M., Huber, H., Mayers, J. L. and Wright, G. F., Can. J. Chem. 40 (1962) 2278

[13] Darnell, A. J., McCollum, W. A. and Yosim, S. J., J. Phys. Chem. 73 (1969) 4116.

[14] Srivastava, K. K., Goyal, D. R., IQbal Krishan and LakShminaraYan, K. N., Indian J. Pure Appl. Phys., accepted for publication. 